http://jmscr.igmpublication.org/home/ ISSN (e)-2347-176x ISSN (p) 2455-0450 crossref DOI: https://dx.doi.org/10.18535/jmscr/v7i7.118

Journal Of Medical Science And Clinical Research

\title{
Knowledge Attitude and Practices of Parents of Children with Febrile Seizure
}

\author{
Authors \\ Dr Ambuj Shandil ${ }^{*}$, Dr Pooja Thakur ${ }^{2}$, Dr Abhinay Sharma ${ }^{3}$, Dr Arnav Shandil ${ }^{4}$, \\ Dr Ishaan Chauhan ${ }^{5}$, Dr Kalpana Sharma ${ }^{6}$, Dr Daleep Tegta ${ }^{7}$ \\ ${ }^{1}$ MD Pediatrics Civil Hospital Theog, Distt Shimla, H.P. India \\ ${ }_{2,3,4,5,6,7}$ Medical Officer Civil Hospital Theog, Distt Shimla, H.P. India \\ *Corresponding Author \\ Dr Arnav Shandil, MD \\ Civil Hospital Theog, Distt Shimla, H.P. India
}

\begin{abstract}
Aim: Knowledge, attitude and practices of parents of children who suffer febrile convulsions are limited leading to unnecessary anxiety and apprehension.

Settings and Design: Prospective questionnaire based study in a tertiary care centre carried over a period of one year.
\end{abstract}

Subjects and Methods: 32 parents of consecutive children presenting with febrile convulsion were enrolled.

Statistical Analysis Used: Chi-square test.

Results: 23 parents (71.9\%) could not recognise the convulsion; 87.5\% (28) did not carry out any intervention prior to getting the child to the hospital. The commonest immediate effect of the convulsion on the parents was fear of death $(n=25,78.1 \%)$ followed by fear of future development of epilepsy $(n=21$, $65 \%)$, fear of recurrence $(n=20,62.5 \%)$ and fear of brain damage $(n=14,43.75 \%)$. Before the onset of seizure, only 3 parents $(9.3 \%)$ knew that high grade fever can cause seizure in children and the remaining 29 (91\%) were unaware of any such relationship between fever and seizure onset. Predominant long term concerns of parents included fear of future development of epilepsy $(n=21,65 \%)$, fear of recurrence $(n=20$, $62.5 \%)$ and fear of brain damage $(n=14,43.75 \%)$. On enquiring further, 23 (72\%) parents were not worried about their other unaffected child, remaining 9(28\%) were worried mostly about occurrence of epilepsy in healthy sibling of the affected child. Of the total of 32 parents interviewed, 28(87.5\%) did not have any thermometer at home. Amongst the remaining 5 (12.5\%) who were having thermometer, only 3 knew how to use it properly. Only 1 parent knew how to measure temperature by axillary method and remaining 2 were using temperature by oral placement of thermometer. None of the parents knew about normal temperature.

Conclusions: The parental fear of fever and febrile convulsion is a major problem with serious negative consequences affecting daily familial life.

\section{Introduction}

By definition febrile seizure are seizures occurring

between 6 to 60 months of life, with temperature of 38 degree $\mathrm{C}(100.4 \mathrm{~F})$ or higher, and are not the result of CNS infection or any metabolic imbalance and that occur in absence of history of 
previous afebrile seizures ${ }^{1}$.A simple febrile seizure is primary generalized toni- clonic attack associated with fever lasting for maximum of 15 min. and not reoccurring within 24 hour period. A complex febrile seizure is more prolonged $(>15$ $\min$ ), is focal or reoccurs within 24 hour period

Between 2 to $5 \%$ of neurologically healthy infants and children between age group of 6 months to 6 year experience at least 1 (usually simple) febrile seizure ${ }^{2}$. Simple febrile seizure do not have increased risk of mortality although they are understandably concerning for parents when they first witness them. Complex febrile seizure have 2 fold increase in mortality ${ }^{3}$. Febrile seizure recur in about $30 \%$ of those experiencing $1^{\text {st }}$ episode, in $50 \%$ after 2 or more episodes of febrile seizures and in $50 \%$ in infants younger than 1 year old at the time of onset of febrile seizure ${ }^{4,5}$. Parents witnessing $1^{\text {st }}$ seizure are so much shocked that most of them think that their children are going to die soon ${ }^{6}$. To decrease this parental apprehension and anxiety, it is very important that they should have correctknowledge about febrile convulsions and their relation with fever and its good prognosis. Most of the parents are so terrified watching $1^{\text {st }}$ episode of seizure that they develop so called fever phobia turning each fever episode in their child into a nightmare ${ }^{7}$. Literature stating natural history and etiology of febrile seizure are numerous but information about knowledge, attitude and practices of parents of parents of such children who suffer febrile convulsions are limited. Hence, this study was planned in secondary health care center setting (first referral unit) to study the knowledge, attitude and practices of parents with children suffering from febrile seizure.

\section{Subject and Methods}

This was a prospective study done at Civil hospital Theog, Himachal Pradesh, over a period of 1 year. Thirty-two parents with children with febrile seizures were enrolled after a proper informed consent of parents. Parents were interviewed on basis of a predesigned questioner at the time of discharge of their child from the hospital after observation period of 24-48 hours or at the time of follow up visit. Febrile seizures were diagnosed on basis of children presenting with seizures during a febrile illness, all those children who had afebrile seizures or seizures due to any other cause were reasonably excluded and those children in whom doubt existed about diagnosis or with atypical presentations were also excluded. A questionnaire comprising of 25 questions was developed and used in this study. Socio-economic class was determined using Kuppuswamy scale ${ }^{8}$. And details about age atonset of first episode of febrile seizure, previous history of seizure, medications and demographic details were obtained and entered in the pro forma. Questions were asked to parents regarding awareness and complications of convulsions, about source of their knowledge about seizure and how they $1^{\text {st }}$ recognised and responded to seizure in their child. They were also questioned if temperature was measured or if fever was diagnosed arbitrarily, availability of thermometer, knowledge about normal temperature range, how to use thermometer correctly and their concerns and worries about their child and other siblings. At the end of this interview, parents' doubts were entertained and they were explained about febrile seizures, its course and home methods to prevent onset of febrile seizures, how to manage seizure, if preventive measures fail and child starts throwing convulsions, how to measure temperature (keeping bulb of thermometer in roof of dry axilla for at least 5 minutes) and also touch method of temperature assessment. The results were analysed by using Chi-square tests.

\section{Results}

32 questionnaire were assessed and analysed at the end of 1 year period. Among the affected infants and children 27(84.3\%) were boys and 5 were girls $(15.6 \%)$. The age of children presenting with febrile convulsions were 1 year to 6 years. Of these children, 19 had single seizure $(59.3 \%)$ and 
13 had recurrent seizures $(40.6 \%)$. The mean age of onset of convulsion was 29.5 months.

Nine $(28.1 \%)$ of 32 parents were able to recognise the $1^{\text {st }}$ episode of convulsions in their child as seizures and remaining 23(71.9\%) interpreted convulsions as shivering $(\mathrm{n}=9,39 \%)$, loss of consciousness/ altered sensorium $(\mathrm{n}=8,34.7 \%)$ fainting spell $(n=4,17.4 \%)$, lethargy $(n=2,8.6 \%)$. $26(81.2 \%)$ parents attributed convulsive activity to high fever and remaining $6(18.75 \%)$ did not have an idea about cause of the convulsion. Parents with previous knowledge about seizure were more proactive in bringing their children to hospital. Twenty eight parents $(87.5 \%)$ did not carry out any home intervention prior to bringing their child to us while the other $4(12.5 \%)$ used measures like shaking the baby, sponging. None of the parents were aware of any risk of aspiration of vomitus or any preventive measures like laying the child to one side in order to prevent aspiration. The commonest immediate concerns of parents of child with seizures was fear of death $(n=25$ $78.1 \%$ ) followed by fear of future development of epilepsy $(n=21,65 \%)$, fear of recurrence $(n=20$, $62.5 \%)$ and fear of brain damage $(n=14,43.75 \%)$.

Before the onset of seizure, only 3 parents $(9.3 \%)$ knew that high grade fever can cause seizure in children and the remaining 29 (91\%) were unaware of any such relationship between fever and seizure onset. Among those 3 parents, one was a health care professional and remaining two were teachers. For $56 \% \quad(n=18)$ each single episode of fever was like a nightmare. Main long term concerns of parents included fear of future development of epilepsy $(n=21,65 \%)$, fear of seizure recurrence $(n=20,62.5 \%)$ and fear of brain injury $(n=14,43.75 \%)$. On further enquiry, $23(72 \%)$ were not worried about their other unaffected child; remaining $9(28 \%)$ were worried mostly about occurrence of epilepsy in healthy sibling of the affected child.

Of the total of 32 parents interviewed, 28(87.5\%) did not have any thermometer at home. Amongst the remaining $5(12.5 \%)$ who were having thermometer, only 3 knew how to use it properly.
Only 1 parent knew how to measure temperature by axillary method and remaining 2 were using temperature by oral placement of thermometer. None of the parents knew about normal temperature range. Parents of children with recurrent convulsions although were able to recognize seizure and were more proactive with management strategies like sponging and antipyretics use, the accurate documentation of temperature was not done and most of the times, they were too relying on touch method for temperature assessment.

With regards of socio-economic classes in our study group, prior awareness of febrile convulsions were significantly higher in socioeconomic class II and III, the same group was more aware of preventive measures then those from socio-economic group IV and V

\section{Discussion}

For most of health care professionals, encountering a febrile seizure in their child may be a common experience devoid of any sort of worrisome implications but in contrast; for a non health care professional, inexperienced parents witnessing their chid throwing a fit is a frightening experience. The severe psychological reactions of most of such parents to febrile convulsions in their child contrasts with a doctor's consideration of febrile seizure as a benign and simple phenomenon. In our study parents of 32 children who presented to us over a period of 1 year were interviewed on basis of a preformulated questionnaire. Our study found out that $72 \%$ of the parents knew nothing about febrile seizure when their child had $1^{\text {st }}$ episode of febrile convulsions interpreting convulsions as shivering ( $\mathrm{n}=9,39 \%)$, loss of consciousness/ altered sensorium $(\mathrm{n}=8,34.7 \%)$ fainting spell $(n=4,17.4 \%)$, lethargy $(n=2,8.6 \%)$. In 26(81.2\%) parents this unawareness of seizures was noted to be higher than that quoted in other studies in developing countries ${ }^{9,10}$. The commonest immediate concerns of parents of child with seizures was fear of death $(n=2578.1 \%)$ followed 
by fear of future development of epilepsy $(n=21,65 \%)$, fear of recurrence $(n=20,62.5 \%)$ and fear of brain damage $(n=14,43.75 \%)$. Our findings were supported by similar findings shown by Van Stuijvenberg et.al who stated that fear of their child was dying was a concern in $47 \%$ during initial seizure episode ${ }^{11}$. In our study fear of death due to seizure was most common concern in parents seen in $78 \%$ parents, the reason of this increase is probably the poor socioeconomic strata of population that we cater and also due to lack of proper education. Similarly Baumer JH et al stated that fear of death was major concern among parents with febrile seizures ${ }^{6}$.

In our study, twenty eight parents $(87.5 \%)$ did not carry out any home intervention prior to bringing their child to us, this incidence was much higher than that observed in some other studies which varies from 38 to $60 \%^{4,10}$. It is equally distressing to see that most of the parents are unaware about methods to prevent seizures and their complications. Also in our study we noted that an overwhelming large number of parents (almost all )were unaware about normal body temperatures and among total of 32 parents, $87.5 \%$ didn't even had thermometer at home, these also included families whose children had more than 1 episode of febrile seizures, and in even those $12.5 \%$ having thermometer at home only $9 \%$ knew how to properly measure temperature.

\section{Conclusion}

Explaining parents about febrile seizure, its relation to fever, benign nature of this disease and addressing their concerns about recurrence, will help in allaying their anxiety. There is a constant need to impart additional skills among parents of children with febrile seizures. Knowledge about normal and abnormal temperatures and how to measure and interpret temperatures should be taught to parents and their doubts should be addressed. Confidence building in parents, help them to panic less and to undertake necessary steps like giving antipyretics and tepid sponging when they encounter their child having fever.
Positioning of children in left lateral position to prevent aspiration during a vomiting episode needs to be highlighted. The harmful practices like vigorous shaking of baby, slapping, forceful closing and opening of mouth should be strongly discouraged. In a study by Huang et al studying effects of educational programme on parents with febrile seizures, concluded that a significant improvement occurred in knowledge, negative attitude, anxiety towards febrile seizures ${ }^{12}$. There are concerns about overburdening parents with information, Wassmer et al showed in their study that such information are very well retained by the parents, hence simple measures like taking body temperatures and measures to treat fever should be taught to parents during the health care contact like immunization

\section{References}

1. Patterson JL, Carapetian SA, Hageman JR, Kelley KR. Febrile seizures. Pediatr Ann. 2013 Dec;42(12):249-54.

2. Huang YY, Li G, Sun LS. Epidemiology and Resource Utilization of Simple Febrile Seizure-associated Hospitalizations in the United States, 2003-2012. J Neurosurg Anesthesiol. 2019 Jan;31(1):144-50.

3. Smith DK, Sadler KP, Benedum M. Febrile Seizures: Risks, Evaluation, and Prognosis. Am Fam Physician. 2019 Apr 1;99(7):445-50.

4. Rutter N, Metcalfe DH. Febrile convulsions--what do parents do? Br Med J. 1978 Nov 11;2(6148):1345-6.

5. García Peñas JJ. [Evaluation of a child with a first unprovoked seizure]. Medicina (Mex). 2018;78 Suppl 2:6-11.

6. Baumer JH, David TJ, Valentine SJ, Roberts JE, Hughes BR. Many parents think their child is dying when having a first febrile convulsion. Dev Med Child Neurol. 1981 Aug;23(4):462-4.

7. Kramer MS, Naimark L, Leduc DG. Parental fever phobia and its correlates. Pediatrics. 1985 Jun;75(6):1110-3. 
8. Sharma R. Revised Kuppuswamy's Socioeconomic Status Scale: Explained and Updated. Indian Pediatr. 2017 Oct 15;54(10):867-70.

9. Balslev T. Parental reactions to a child's first febrile convulsion. A follow-up investigation. Acta Paediatr Scand. 1991 Apr;80(4):466-9.

10. Kürügöl NZ, Tütüncüoglu $\mathrm{S}$, Tekgül $\mathrm{H}$. The family attitudes towards febrile convulsions. Indian J Pediatr. 1995 Feb;62(1):69-75.

11. van Stuijvenberg M, de Vos S, Tjiang GC, Steyerberg EW, Derksen-Lubsen G, Moll HA. Parents' fear regarding fever and febrile seizures. Acta Paediatr Oslo Nor 1992. 1999 Jun;88(6):618-22.

12. Huang MC, Liu CC, Huang CC. Effects of an educational program on parents with febrile convulsive children. Pediatr Neurol. 1998 Feb;18(2):150-5. 